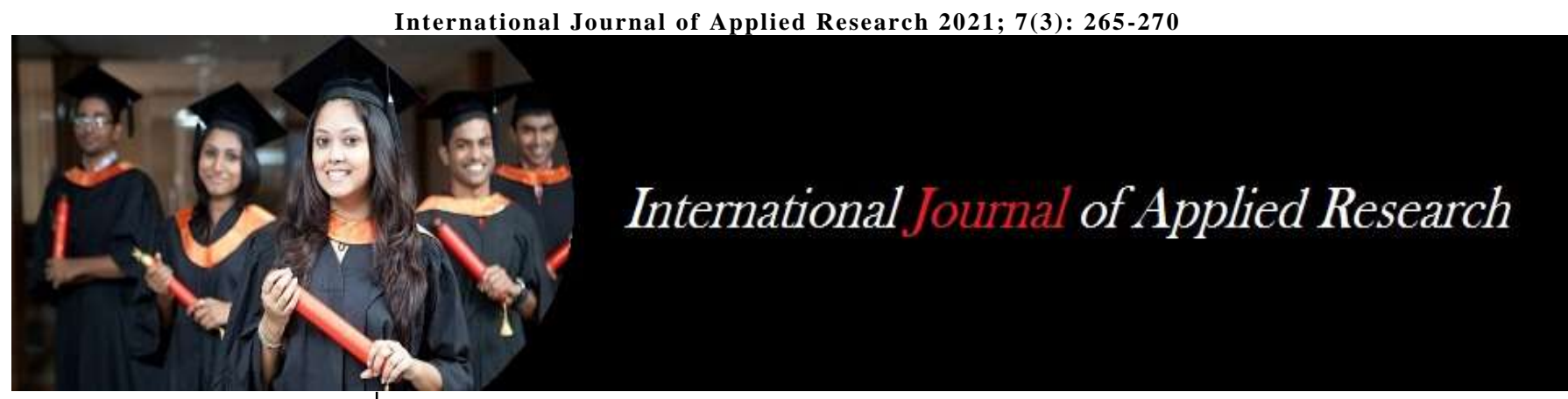

ISSN Print: 2394-7500

ISSN Online: 2394-5869

Impact Factor: 8.4

IJAR 2021; 7(3): 265-270

www.allresearchjournal.com

Received: 19-12-2020

Accepted: 02-02-2021

\section{Dr. Kumar}

Assistant Professor of Zoology,

Government College for

Women (Autonomous),

Mandya, Karnataka, India
Corresponding Author:

Dr. Kumar

Assistant Professor of Zoology,

Government College for

Women (Autonomous),

Mandya, Karnataka, India

\section{Earthworm - microbe interactions}

\section{Dr. Kumar}

\section{Abstract}

The digestive system of earthworms consists of a pharynx, oesophagus and gizzard ('reception zone') followed by an anterior intestine that secretes enzymes and a posterior intestine that absorbs nutrients. During progress through this digestive system there is a dramatic increase in numbers of microorganisms of up to 1000 times. There is experimental evidence that microorganisms provide food for earthworms. Bacteria are of minor importance in the diet, algae are of moderate importance; protozoa and fungi are major sources of nutrients. Worms, produced under sterile conditions, could live on individual cultures of certain bacteria, fungi and protozoa, but grew best on various mixtures of microorganisms.

Symbiotic interactions between earthworms and microorganisms break down and fragment organic matter progressively, finally incorporating it into water-stable aggregates. The mineral nutrients in earthworm casts and lining earthworm burrows are in a form readily available to plants. There is evidence that interactions between earthworms and microorganisms not only provide these available nutrients, but stimulate plant growth indirectly.

Keywords: Earthworms, microorganisms, microflora, burrows, casts, bacteria, plants, nutrients, decomposition

\section{Introduction}

Earthworms are natural invertebrates of agro-ecosystem belonging to the Phylum Annelida, Class Chaetopoda and Order Oligochaeta. Dominant in the temperate and tropical soils, they are the first group of multicellular eucoelomate invertebrates to have successfully inhabited terrestrial environment. Popularly called 'ecosystem engineers', they play an important role in many soil ecosystems and are among the numerous ranges of burrowing organisms which improve soils. Recognized as the key indicators of sustainable soil health and fertility, they actively redesign the physical structure of the soil environment by their activities of ingesting litter and soil particles, forming burrows, depositing casts on the soil surface and translocating soil particles. The activities of earthworms in soils have profound impact on the soil ecosystem functioning as well as on the types and numbers of micro-flora and fauna.

Gilbert White, a European naturalist postulated in 1789 the importance of burrowing and feeding by earthworm on the fertility of soil. He made the following observations in his journal 'The Natural History of Selbourne': 'Worms seem to be the great promoters of vegetation by boring, perforating, and loosening the soil, and rendering it pervious to rains and the fibers of plants; by drawing straws and stalks of leaves and twigs into it; and most of all, by throwing up such infinite numbers of lumps of earth called worm-casts, which, being their excrement, is a fine manure for grain and grass'. Charles Darwin was the first to document in 1881 the increased plant litter decomposition due to the activities of earthworms in his book 'The formation of Vegetable Mould through the action of Worms'. Consequent to Darwin's observations, the role of earthworms in litter decomposition and fertility of soil has been the subject of in-depth study. They are not necessarily the essential inhabitants of the soil, but their presence can be an indicator of the quality of soil.

Earthworms alter the physical structure of soil for good by their tunneling activity. Such activity improves soil aeration, porosity and permeability, increases moisture absorption and availability of moisture to plants. Generally, more active in moist soils, they contribute to the maintenance of soil fertility in at least three ways: (i) build and maintain a soil structure based on resistant macro-aggregates; (ii) release nutrients from the plant residues to the soil organic matter; and (iii) physically protect humus inside compact globular casts. 
Earthworm activity creates structures, globular and granular casts and galleries that modify soil aggregation and porosity as well as the communication between pores. Earthworm feeding increases the interaction among microflora, thereby improving the flow and exchange of nutrients.

Earthworms are presumed to be the most ancient soil animals having started colonising terrestrial environments about 600 million years ago and are the most predominant soil fauna which do not inhabit dry and cold climates. Earthworms live mostly in horizontal burrows, selecting food from the soil, often feeding on organic materials that are on or just below the soil surface, deposit casts within their burrows or in other spaces within the soil. There are about 3000 species of earthworms distributed all over the world and about 590 species in India were reported by Julka (2009) ${ }^{[2]}$. Lampito mauritii is widely distributed earthworm in India. It was reportedly spotted at different agroecosystems as in gardens, manure heaps and fields especially in South India. Next to L. mauritii, Pontoscolex corethrurus, Polypheretima elongata, Perionyx excavatus, and Dichogaster bolaui are other types of earthworms widely distributed in the country.

\section{Types of Earthworms}

Three ecological categories of earthworms have been described each of which creates earthworm spheres with differing characteristics.

\section{Epigeic (Surface soil and litter species)}

Epigeic species live in, consume and partially digest surface litter rarely ingesting soil particles. They live in the litter layers' subject to drought, high temperatures and predator presence. These earthworms are generally small and pigmented (green or reddish) with rapid movements and are adapted to highly variable moisture and temperature conditions at the soil surface. Generally, found in compost piles, they are unlikely to survive in the low organic matter environment of soil. Epigeics have a short gut transit time and they probably depend on a rapid response of gut microbes to aid in digestion. Examples include Dendrobaena octaedra, D. attemsi, D. rubidus, Eiseniella tetraedra, Heliodrilus oculatus and Lumbricus rubellus.

\section{Anecic (Deep-burrowing species)}

Anecics, the dominant earthworms in many temperate region soils, are primarily vertically burrowing species. They feed on surface litter that they generally mix with soil and more or less are permanent refuges in underlying soil horizons. They are large with dark anterodorsal pigmentation and they dig sub-vertical burrows. They often produce characteristic surface features called middens which are circular mound-shaped region around a surface of the burrow's opening. It is a mixture of surface organic materials and soil. These are presumed to act as external rumens where microbes and fauna, attracted to this 'hotspot', enhance decomposition of uningested litter and organic fragments in casts. Examples of Anecic earthworms include Lumbricus terrestris and Apporectodea longa.

\section{Endogeic (Upper soil species)}

Endogeic are the most prevalent earthworms in most tropical environments, particularly in agro-ecosystems. Endogeics are geophagous earthworms that feed on subsurface soil horizons and on soil OM of different qualities. They produce surface and below-ground casts of two main types: globular and granular. Some species move and live in the upper soil strata and feed primarily on soil and associated organic matter. They do not have permanent burrows, and their temporary channels become filled with cast material as they move through the soil progressively passing it through their intestines. Gut microflora are also preferentially stimulated or reduced depending on earthworm and microbe species, soil environment, and food ingested. Examples include Allolobophora chlorotica, Apporectodea caliginosa, A. icterica, A. rosea, Murchieona muldali, Pontoscolex corethrurus and Lampito mauritii.

\section{The Earthworm Sphere}

The area around the earthworm or the earthworm 'sphere' creates a favourable microhabitat for soil microflora and stimulates microbial populations in the soil. The burrow wall that the earthworm creates in the soil, which is directly or indirectly influenced by the earthworm burrowing activity, has been variously called zoosphere, vermisphere or drilosphere. Bouche (1975) ${ }^{[1]}$ defined drilosphere as a zone which is $2 \mathrm{~mm}$ thick around earthworm burrow walls. Lavelle (1987) ${ }^{[4]}$ expanded its meaning to include all soil including microbial and invertebrate populations affected by earthworm activities. Hence drilosphere includes externally produced structures (middens, burrows, diapause chambers, surface and below ground casts), the earthworm surface in contact with the soil and the internal micro environment of the earthworm gut. Earthworm sphere creates a favorable microhabitat for the soil microflora and is constantly changing in space and time. Therefore its importance, as a hot spot of microbial activity in the soil, is now widely accepted.

\section{Soil microorganisms}

Soil, an important factor that influences the productivity of our planet's ecosystems, is vital for the existence of many forms of life and harbours a remarkable biodiversity. Being one of nature's most complex ecosystems, soil contains thousands of different organisms which interact and contribute to the global cycles that make all life possible. Soil forms an intricate network of communities and these communities, again, group themselves as smaller communities occupying specific microhabitats and microniches. The microhabitat of soil is affected in addition to physical and chemical factors by the micro and macro fauna and flora. Microorganisms in soil are critical to the maintenance of soil function in both natural and managed agricultural soils because of their involvement in such key processes as soil structure formation, decomposition of organic matter, toxin removal, and the cycling of carbon, nitrogen, phosphorus, and sulphur. In addition, microorganisms play key roles in suppressing soil borne plant diseases, in promoting plant growth, and in changes in vegetation. Bacteria, fungi and actinomycetes, collectively referred to as the microflora, are both numerous and diverse and show varying degrees of activity in different microhabitats and are in turn influenced by macro organisms.

\section{Earthworms and microbial association}

Earthworms have become the driving forces of the soil microbial community as they modify decomposition processes and soil structure function. Earthworms have 
developed a sort of relationship with the soil microorganisms which has made possible the process of digesting soil organic matter and exploit the organic resources available in the litter and soil, and thereby contribute to the maintenance of soil fertility and soil microbial diversity. Though the soil microorganisms are able to perform almost any chemical transformation during the process of decomposition of organic material, their activity is highly dependent on macroorganisms which influence the environment at larger scales of time and space. While earthworms use organic matter as their nutrient source, microorganisms, ingested along with these nutrient sources, produce the enzymes that make the nutrients available for the worm's use. The ingested microbial populations play a key role in earthworm nutrition by helping in the breakdown of organic matter, particularly the components that the earthworms cannot utilise in their natural state. Scientists interestingly call it the 'Sleeping beauty paradox', because oil microbial communities (the 'Sleeping Beauties') have the ability to digest almost any organic substrate, yet are dormant most of the time because they need carbon that can be assimilated but have a limited ability to move within the soil in order to reach these resources. On the other hand, earthworms (the 'Prince Charming') move within the soil, secrete mucus and provide the suitable temperature, moisture and organic resources within their guts for microbes to be activated. A conditional mutualism is observed between earthworms and soil microorganisms where both indulge in 'mutual exploitation for mutual gain', achieving a better utilisation of the ingested soil organic resources.

Earthworm deposits have a localised effect on microbial behaviour modifying the biological activity of soils. This phenomenon is observed in casts or burrows or both, which are lined with mucus and other deposits. The casts and burrows, which they create, facilitate water and gas transport by mixing soil minerals with organic material. Burrow systems help us understand (i) the actual role of earthworms in the soil ecosystem, (ii) the influence of these burrow systems on soil transfer properties and (iii) the difference in the microbial diversity compared to surrounding soil. Burrows and burrow walls are surrounded by soil rich in nutrients and polysaccharides and are lined with protein rich mucus that gives the burrow walls and castings their consistency. These maintain the stability of the channels by binding soil particles together. In addition to mucus secretions, nitrogen excretion from the earthworm bodies (mostly urea and ammonia) is also added to the burrow walls or to castings or both. The diameter of the burrows varies with the dimensions of the earthworms but is generally in the range of $1-10 \mathrm{~mm}$, which places them among the largest of soil pores. Burrows enable earthworms to select conditions that suit them best within the range of microenvironments available in one or more soil horizons, while retaining access to forage for food at the surface at times when conditions are suitable.

\section{Microflora in Earthworm gut}

The interaction between the microorganisms and the earthworms during the transit of the soil inside their gut is well known. Studies have shown that the microorganisms present in the gut of the earthworms were also present in the soil in which the worms lived and it is unlikely to possess an indigenous microfloral population. Evidences show that the number of microorganisms in the guts is much higher than their number in the surrounding soil. Within a worm there are multitudes of microscopic organisms working hard to aid digestion and produce nutrient-rich compost. These microbes are either swallowed up along with an earthworm's food or are already present in a worm's gut. They include bacteria, fungi, nematodes, and protozoa. Earthworms actually lack the enzymes to break down much of what they eat. So they rely on these microbes to do the same for them. Then the digested organic matter is excreted as a worm cast. During the passage through the earthworm gut, fungal hyphae are digested preferentially, whereas many pass through unaffected. Experiments have shown that earthworms prefer and partly digest rapidly growing cellulolytic fungi like Fusarium and Trichoderma species possibly because they are needed to digest the litter consumed. Such fungi, when passed through the intestine of earthworm, eliminate some of the active stages of fungal spores, hyphae and bacteria. The surviving and resistant microorganisms, together with those in the earthworm burrow wall, provide inocula for colonisation of the newly formed casts. The earthworm gut provides a suitable condition for the survival and growth of microorganisms and it reveals the presence of different kinds of microorganisms which gradually decrease in number in the mid gut and hindgut with fewest in freshly laid casts.

\section{Microflora in Earthworm casts}

Nowak (1975) ${ }^{[5]}$ proposed that the most important effect of earthworms on soils may be the stimulations of microbial activity that occurs in casts. A worm casting is a biologically active mound containing numerous bacteria, enzymes and remnants of plant materials and animal manure that were not digested by earthworm. Earthworm casts significantly affect plant growth through their effects on microorganisms, aggregation of soil, and nutrient supply. They are stable structures characterised more by higher content of nutrients, microbial biomass and activity than by uningested material. Fresh earthworm casts are several times richer in nitrogen, phosphates, potash and other nutrients than the surrounding topsoil due to mineralization taking place in the gut as well as in the casts.

\section{Earthworms produce basically four types of casts}

Globular: consisting of coalescent round or flattened units, generally produced by the larger earthworm species (anecic and endogeic species)

Paste like slurries: mainly produced by endogeic or anecic species and excreted as single mass of soil without a distinct shape, but take irregular shapes once dried

Tall vertical heaps or columns of variable shapes: usually deposited on the soil surface where they are most visible by endogeic and anecicspecises

Granular: typically, in the form of pellet, produced mainly by smaller earthworm species (epigeic, small endogeic, and some anecic species) and distributed on or beneath the soil surface Earthworm casts are the foci from which soil microorganisms can spread into the surrounding soil. Differences in microbial populations in the earthworm casts and surrounding soil are due to either environmental changes within the gut of earthworms or due to the food 
material which provides a rich substrate thereby increasing microfloral activity. Earthworms were found to predate on a variety of fungi such as Nigrospora sphaerica, Helminthosporium sp., Chaetomium sp., Curvularia sp., Rhizopus nigricans, Mucor hiemalis, Fusarium oxysporum, Alternaria solani, Trichoderma viridi, Cunninghamella echinulate, Blastomyces sp., Botryotrichus sp. and Chaetomium glabrum, bacteria such as Bacillus cereus, B. mycoides, Serratia marcescens, E. coli and Enterobacter cloacae, yeast Candida famata and these have been isolated from casts.

\section{Microflora in Earthworm burrows and burrow walls}

Earthworms live mostly in horizontal burrows, selecting food from soil, often feeding on organic materials that are on or just under the soil surface, deposit casts within their burrows or in other spaces within the soil. The burrows they create facilitate water and gas transport by combining soil minerals with organic material. Since one half of the nitrogenous waste of earthworm is excreted through the body surface, it is, presumably, accumulated in the burrow walls and affects the soil microbial community in those areas. Earthworm burrows are important in maintaining soil aeration, drainage and porosity. Burrows and burrow walls are surrounded by soil rich in nutrients and polysaccharides and are lined with protein rich mucus that gives the burrow walls and castings their consistency. These maintain the stability of the channels by binding soil particles together. The burrows can be significantly enriched with oxidised Fe, plant available-P, $\mathrm{N}$ and exchangeable $\mathrm{Ca}$ and $\mathrm{K}$. The diameter of the burrows varies with the dimensions of the earthworms but is generally in the range of $1-10 \mathrm{~mm}$, which places them among the largest of soil pores. Burrows enable earthworms to select conditions that suit them best within the range of microenvironments available in one or more soil horizons, while retaining access to forage for food at the surface at times when conditions are suitable. Earthworm burrow walls harbour distinctive communities of soil animals, e.g. protozoa, nematodes and microarthropods, which, presumably, control microbial activity in these microhabitats. The microenvironment, associated with the walls of earthworm burrow, may be substantially different from soil only a few millimeters away. Burrow walls which are enriched with polysaccharides become buffered to neutral $\mathrm{pH}$ in acid and alkaline substrate through cutaneous mucus secretion and form stable microhabitats for specific active microbial communities. This microenvironment comprises of less than $3 \%$ of the total soil volume but contains $5-25 \%$ of the whole soil microflora and is where some functional groups of bacteria predominate.

\section{Types of burrows formed by earthworms}

Earthworms are grouped into 3 types based on their habitats and the types of burrows they form are different in each case.

1. Burrows formed by anecic earthworms: They are usually vertical for most of their length, sometimes branching near the top to several entrances. They may extend deep into the soil, even up to $3 \mathrm{~m}$ or more and have smooth linings built up by compression of soils and mucus secreted by the earthworms, which probably help to maintain high humidity and reduce water loss.

2. Burrows formed by endogeic earthworms: Their burrows are predominantly horizontal, but have some vertical components and some openings to the soil surface. They too extend deep inside the soils and are smooth walled, with a surface layer usually thinner than that found in burrows of anecics. Many burrows are partly or wholly packed with casts or soil from overlying horizons, carried down by water.

Burrows formed by epigeic earthworms: These are more or less vertical made by species of earthworms that live near the surface as they retreat to enter a resting state in deep soil horizons during dry or cold seasons or return to surface horizons when conditions are favourable for them to resume active life. These burrows generally lack distinct linings; they are, apparently, made quickly; are used only one time and are ephemeral. They often terminate in roughly spherical mucus-lined chambers where individual earthworms take refuge.

The mucous secretions contain high concentrations of organic $\mathrm{N}$ and ammonium and may serve as a substrate for fungi and bacteria. Also, earthworm castings that are ejected in the burrow and subsequently pressed into the side of the burrow wall contain increased quantity of nitrate and ammonium. The abundant nutrient resources for the soil microflora in the burrow walls continue the priming effect of the earthworm gut, thereby increasing over a short period mineralization rates and plant nutrient bioavailability.

Studies also suggest that the structure of the microbial communities within earthworm casts and burrows is different from that in the surrounding or bulk soil. Bacteria significantly concentrate at the surface of the burrow walls and within the adjacent $2 \mathrm{~mm}$ of the surrounding soil. Bacteria are important in soils because they contribute to the carbon cycle by fixation and decomposition. Some bacteria are important decomposers and actinomycetes are particularly effective at breaking down tough substances such as cellulose and chitin. Burrow walls are found to harbour bacteria like Cellulomonas, Promicromonospora, Streptomyces, Myxobacteriales, Aquaspirillum, Alcaligenes, Micrococcus, Acinetobacter, Serratia, Staphylococcus and Enterobacter. Bacteria which prompt plant growth like Pseudomonas, Rhizobium and Azotobacter are also observed in the burrow walls. Generally, a substantial part of the fungal community in burrow walls is typical "litter" species, mainly Trichoderma and Mucor. Apart from these species, Fusarium, Penicillium, Cladosporium, Paecilomyces, Acremonium, Cunnighamella and Aspergillus are also seen. 


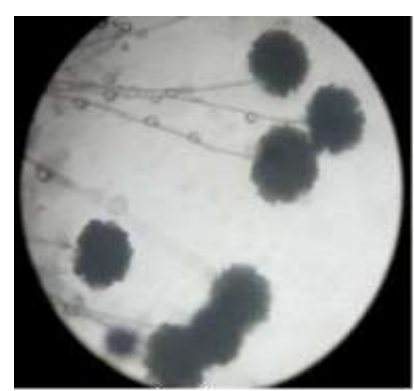

A. niger

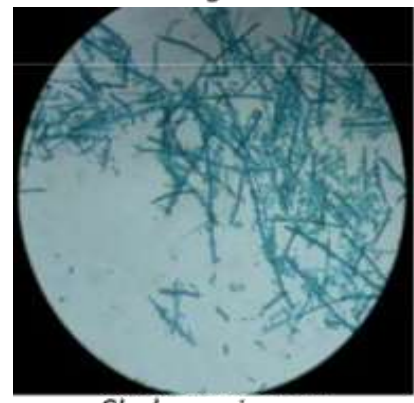

Cladosporium sp.

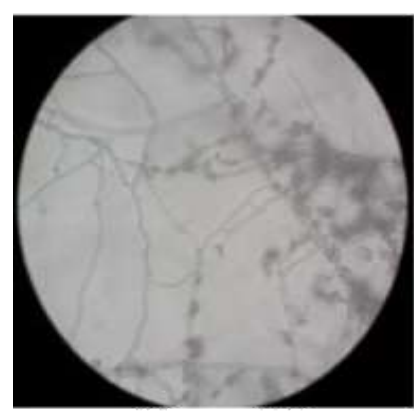

Fusarium oxysporum

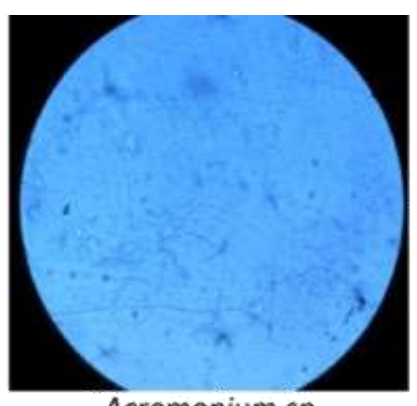

Acremonium sp.

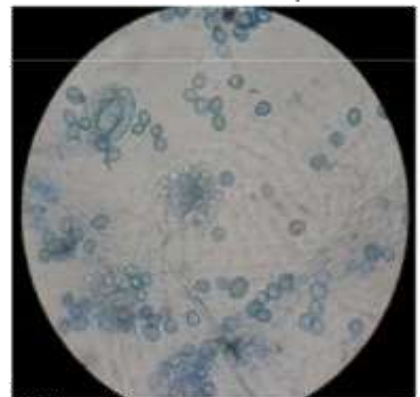

Cunnignhamella elegans

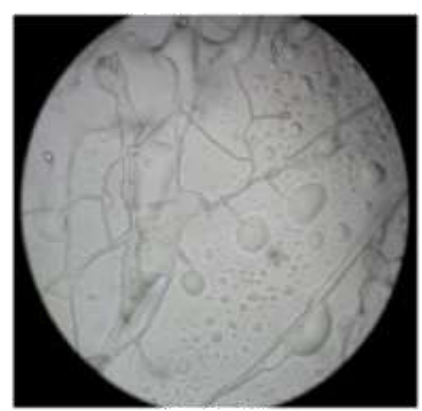

F. solani

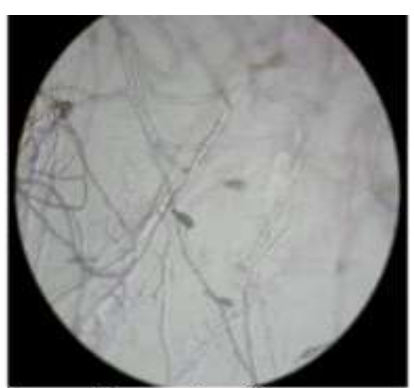

Alternaria alternata
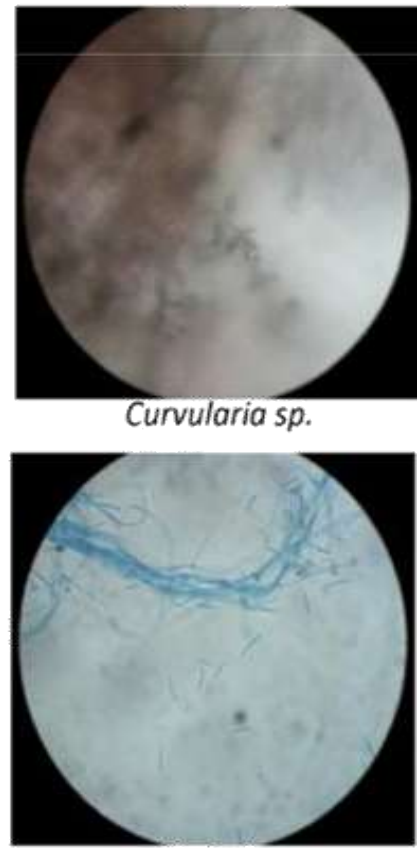

Fpallindoroseum

Fig 1: Fungi from earthworm sphere

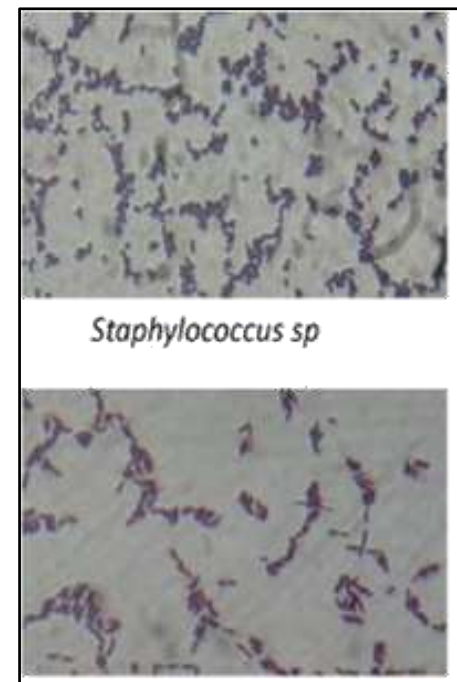

Bacillus cereus

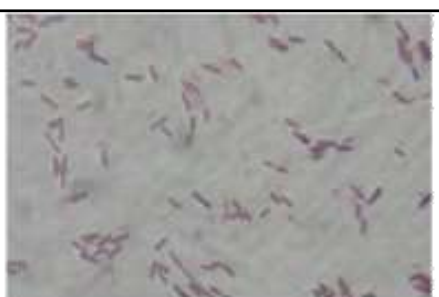

Clostridium sp

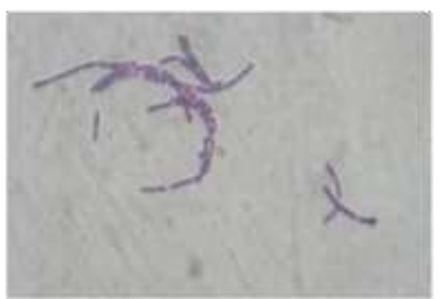

Bacillus subtilis

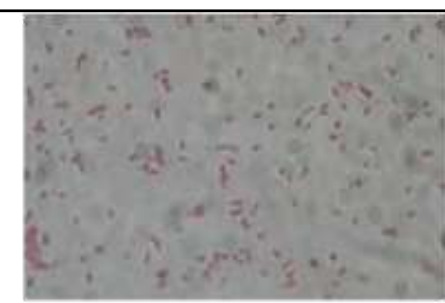

E.colit

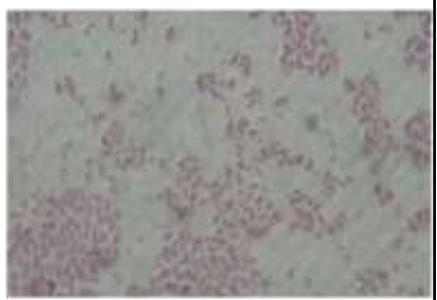

Pseudomonas sp
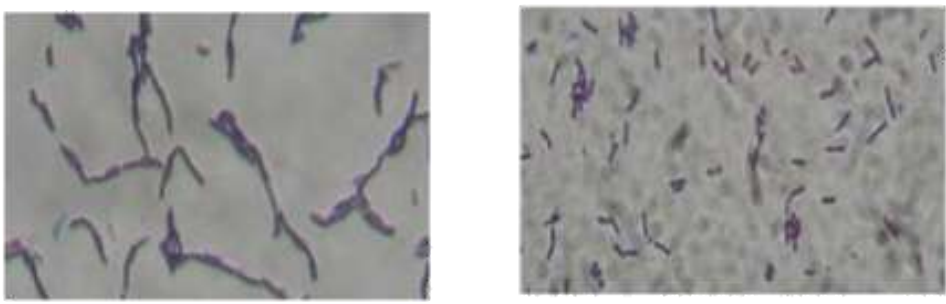

Bacillus sps 


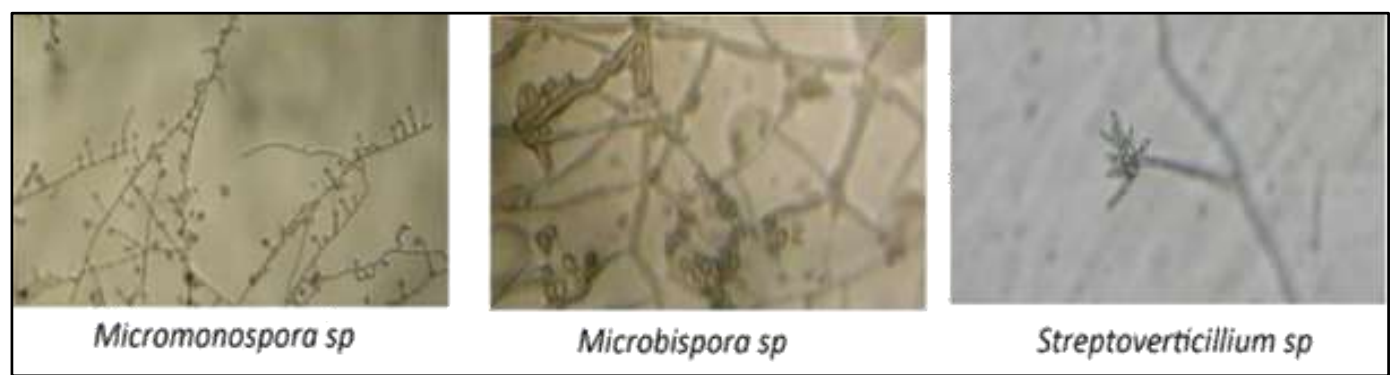

Fig 2: Bacteria and Actinomycetes from earthworm sphere

\section{Conclusion}

The earthworm sphere is constantly changing in space and time as earthworms explore still unaltered soil or re-alter the soil previously processed by communities. Earthworms are important to plant litter decomposition and fertility of soil and their role is complex which involves the assistance of microorganisms. They are the keystone animal group regulating activities of soil microorganisms, plant growth and interactions within soil communities and in turn affecting soil fertility. By modifying decomposition processes and soil structure, they function as driving forces of the soil microbial community. It is now well established that the activities of earthworms in soils have profound impact on the soil ecosystem functioning as well as on the types and numbers of micro-flora and micro-fauna.

\section{References}

1. Bouché MB. Faunal action on the states of the organic matter in ecosystems. In: G Kilbertus, O. Reisinger, A. Mourey and J. A Cancela da Fonseca (editors) Humification and biodegradation. Sarruguemines, Pierron 1975, 157-168.

2. Julka JM, Paliwal R, Kathireswari P. Biodiversity of Indian earthworms-an overview, in: C. A. Edwards, R. Jayaraaj and I. A. Jayraaj, (Editors) Proceedings of Indo-US Workshop on Vermitechnology in Human Welfare, Coimbatore, India 2009, 36-56.

3. Kale RD, Karmegam N. The Role of Earthworms in Tropics with Emphasis on Indian Ecosystems. Applied Environmental Soil Science 2010.

4. Lavelle P. The importance of biological processes in productivity of soils in the humid tropics. In: R. E. Dickinson and J. Lovelock (editors) Geophysiology of Amazoni. Wiley \& Sons, New York 1987, 175-214.

5. Nowak E. Population densities of earthworms and some elements of their production in several grass- land environments. Ekologia Polska 1975;23:459-491. 